\title{
Grit and Academic Performance in Doctor of Physical Therapy Students
}

Scott Richardson

Franklin Pierce University, richardsons@franklinpierce.edu

Michael Scotto

Franklin Pierce University, Scottom18@live.franklinpierce.edu

MayAnne Belcina

Franklin Pierce University, Belcinam18@live.franklinpierce.edu

Richa Patel

Franklin Pierce University, Patelr18@live.franklinpierce.edu

Kevin Wiener

Franklin Pierce University, Wienerk18@live.franklinpierce.edu

Follow this and additional works at: https://nsuworks.nova.edu/ijahsp

Part of the Physical Therapy Commons

\section{Recommended Citation}

Richardson S, Scotto M, Belcina M, Patel R, Wiener K. Grit and Academic Performance in Doctor of Physical Therapy Students. The Internet Journal of Allied Health Sciences and Practice. 2020 Jan 01;18(4), Article 13.

This Manuscript is brought to you for free and open access by the College of Health Care Sciences at NSUWorks. It has been accepted for inclusion in Internet Journal of Allied Health Sciences and Practice by an authorized editor of NSUWorks. For more information, please contact nsuworks@nova.edu. 


\title{
Grit and Academic Performance in Doctor of Physical Therapy Students
}

\begin{abstract}
Purpose: The purpose of this study was to determine whether a physical therapy student's level of grit positively correlates to graduate school grade point average. Methods: Participants were a convenience sample recruited from the class of 2021 in the Doctor of Physical Therapy program at Franklin Pierce University in Goodyear, Arizona. Subjects completed the Short Grit Scale (Grit-S) as a measure of grit. These scores were compared with participants' graduate school grade point average using a Spearman Rho statistical test with data analysis completed using SPSS software. Results: 27 participants (15 males, 12 females) with mean grit score of $3.76 \pm 0.48$ and mean grade point average $3.72 \pm 0.18$. Spearman Rho correlation was $.463(\mathrm{p}<.05)$. Conclusion: A significant moderate positive correlation between grit and graduate school grade point average in physical therapy students was found. These findings indicate preliminary evidence that may be useful for admissions considerations for DPT programs.
\end{abstract}

\section{Author Bio(s)}

Scott Richardson, PT, PhD, is an assistant professor in the Doctor of Physical Therapy program at Franklin Pierce University located in Goodyear Arizona. He has received the Advanced Competency in Home Health Care from the American Physical Therapy Association.

MayAnne Belcina, Richa Patel, Michael Scotto and Kevin Wiener are all Doctor of Physical Therapy students at Franklin Pierce University located in Goodyear Arizona. 


\title{
IJAHSP \\ The Internet Journal of Allied Health Sciences and Practice
}

Dedicated to allied health professional practice and education

Vol. 18 No. 4 ISSN 1540-580X

\section{Grit and Academic Performance in Doctor of Physical Therapy Students}

\author{
Scott Richardson \\ Michael Scotto \\ May Ann Belcina \\ Richa Patel \\ Kevin Wiener \\ Franklin Pierce University \\ United States
}

\begin{abstract}
Purpose: The purpose of this study was to determine whether a physical therapy student's level of grit positively correlates to graduate school grade point average. Methods: Participants were a convenience sample recruited from the class of 2021 in the Doctor of Physical Therapy program at Franklin Pierce University in Goodyear, Arizona. Subjects completed the Short Grit Scale (Grit-S) as a measure of grit. These scores were compared with participants' graduate school grade point average using a Spearman Rho statistical test with data analysis completed using SPSS software. Results: 27 participants (15 males, 12 females) with mean grit score of $3.76 \pm 0.48$ and mean grade point average $3.72 \pm 0.18$. Spearman Rho correlation was $463(p<$ .05). Conclusion: A significant moderate positive correlation between grit and graduate school grade point average in physical therapy students was found. These findings indicate preliminary evidence that may be useful for admissions considerations for DPT programs.
\end{abstract}

Keywords: grit, grade point average, physical therapy, admissions 


\section{INTRODUCTION}

It is of perennial interest for Doctor of Physical Therapy programs to select student applicants suitable for the academic rigor of graduate level studies. Currently, physical therapy student capabilities are measured primarily by undergraduate grade point average and Graduate Record Examination scores with only a secondary focus on recommendation letters and submitted essays. ${ }^{1}$ Conspicuously absent is a character assessment indicative of a student's prospective success. Scholastic achievement is determined not only by intellectual aptitude but also the presence of particular non-cognitive personality traits. ${ }^{2} \mathrm{~A}$ growing area of research involves consideration and measurement of these non-cognitive traits for graduate students. ${ }^{2-4}$

One of the most salient and determinant measures of these characteristics is grit. University of Pennsylvania psychology professor Angela Duckworth defines grit as "the tendency to sustain interest in and effort towards long-term goals 5 . Duckworth has developed and extensively published an empirical validated Grit Scale (Grit-S) questionnaire for quantifying grit in individuals. ${ }^{5}$

Research utilizing this scale has revealed a positive correlation between grit and academic performance across a variety of domains including undergraduate studies, medical school, pharmacy school, and other doctorate programs in business, education and psychology..$^{6-8}$ Research from Calo et al compared grit levels of physical therapy, medical, nursing, and pharmacy students with recommendations that future research should focus on potential correlations between grit and academic performance..$^{9}$ Grit has been shown to correlate with more effective stress coping among health profession students suggesting a greater capacity to thrive in challenging academic environments. ${ }^{10}$ Miller-Matero et al demonstrated a positive correlation between grit levels and academic performance in medical students. ${ }^{6}$ Furthermore, Palisoc et al found that pharmacy students with higher grit scores were more likely to pursue postgraduate training with higher rates of academic success. ${ }^{11}$

To this end, including student's grit scores would provide a more complete student profile by revealing their potential to cope with the many stressors associated with achieving academic success. The most accurate appraisal of student abilities will maximize program outcomes and ultimately produce effective physical therapy clinicians. To date, no research has investigated the correlation between grit and academic performance among physical therapy students. It is the purpose of this study to determine the correlation between graduate level grade point average and grit in Doctor of Physical Therapy students.

\section{Methods}

Participants

Participants included a convenience sample of 27 student volunteers (15 females) with age range 23-34 years of age recruited from the 2021 Arizona cohort of the Franklin Pierce University Doctor of Physical Therapy Program at the Arizona Campus.

\section{Data Collection}

Approval from the Franklin Pierce University Institutional Review Board was granted prior to data collection. Participation was voluntary and all participants completed a consent form before proceeding to an online survey. The validated Short Grit Scale (GRIT-S) was accessible to all participants via encrypted online survey. ${ }^{5}$ The Short Grit Scale developed by Angela Duckworth is a self-reported questionnaire in which participants assess their consistency of interest, level of passion, and perseverance in the context of obtaining long-term goals indicated via a 5-point Likert Scale. The Likert Scale has been shown to have predictive validity and test retest reliability. ${ }^{5}$ The scale includes 8 items with scores ranging from one to five corresponding to "not like me at all" to "very much like me," respectively. Furthermore, questions are keyed as either positive or negative referring to the score marked on that particular question as either raising or lowering the subject's overall grit score. (See Table 1 for the positively and negatively keyed items.) After accounting for the positive and negative values for each question, the remaining value is averaged to obtain the subject's overall grit score. The maximum score on this scale is 5 (extremely gritty), and the lowest scale on this scale is 1 (not at all gritty). Grit scores were then linked to the corresponding participants graduate grade point average by the principle investigator. Cumulative grade point average from all classes in the first six terms of the graduate DPT curriculum were used. Participants were de-identified to ensure participant anonymity.

\section{Data Analysis}

Analysis for differences in grit scores between genders was performed using a Mann Whitney $U$ test. Analysis for differences in grade point average scores between genders was performed using an unpaired $t$ test. Means were calculated for grit scores and grade point averages. Grit scores were compared with graduate school grade point average utilizing a Spearman Rho analysis using SPSS version 25 . 
Table 1. Short Grit Scale questions are keyed as either contributing to a higher grit score (positively keyed) or reducing grit score (negatively keyed items).

\begin{tabular}{|l|l|}
\hline Positively Keyed Items & Negatively Keyed Items \\
\hline I am diligent. & $\begin{array}{l}\text { New ideas and projects sometimes distract me from previous } \\
\text { ones. }\end{array}$ \\
\hline Setbacks don't discourage me. & $\begin{array}{l}\text { I have difficulty maintaining my focus on projects that take } \\
\text { more than a few months to complete. }\end{array}$ \\
\hline I finish whatever I begin. & $\begin{array}{l}\text { I have been obsessed with a certain idea or project for a } \\
\text { short time but later lost interest. }\end{array}$ \\
\hline I am a hard worker. & I often set a goal but later choose to pursue a different one. \\
\hline
\end{tabular}

\section{RESULTS}

Sample Characteristics

Participants included 15 females and 12 males with a mean age of $26 \pm 3.36$ ranging from 23-34 years of age. Results from the Mann-Whitney $U$ test showed that effects of sex differences on grit scores $(p=.368)$ were insignificant and an unpaired t-test showed that effects of sex differences on grade point average $(p=.252)$ were insignificant.

Table 2. Grit and GPA Scores

\begin{tabular}{|c|c|c|c|c|c|}
\hline Characteristic & N & Minimum & Maximum & Mean & Std. Dev. \\
\hline Grit & 27 & 2.50 & 4.40 & 3.72 & 0.45 \\
\hline GPA & 27 & 3.20 & 3.96 & 3.72 & 0.18 \\
\hline
\end{tabular}

\section{Grit Score Analysis}

Mean grit score for all participants was $3.72 \pm 0.45$. Grit scores were calculated with average of scores for four positive and four negative scored items.

\section{Grade Point Average Analysis}

Mean grade point average for all participants was $3.72 \pm 0.18$. A Spearman Rho analysis was utilized to determine the relationship between grade point averages and grit score values. There was a moderate, positive significant correlation between grade point averages and grit scores $\left(r_{s}=0.462, p<0.05\right)$.

।

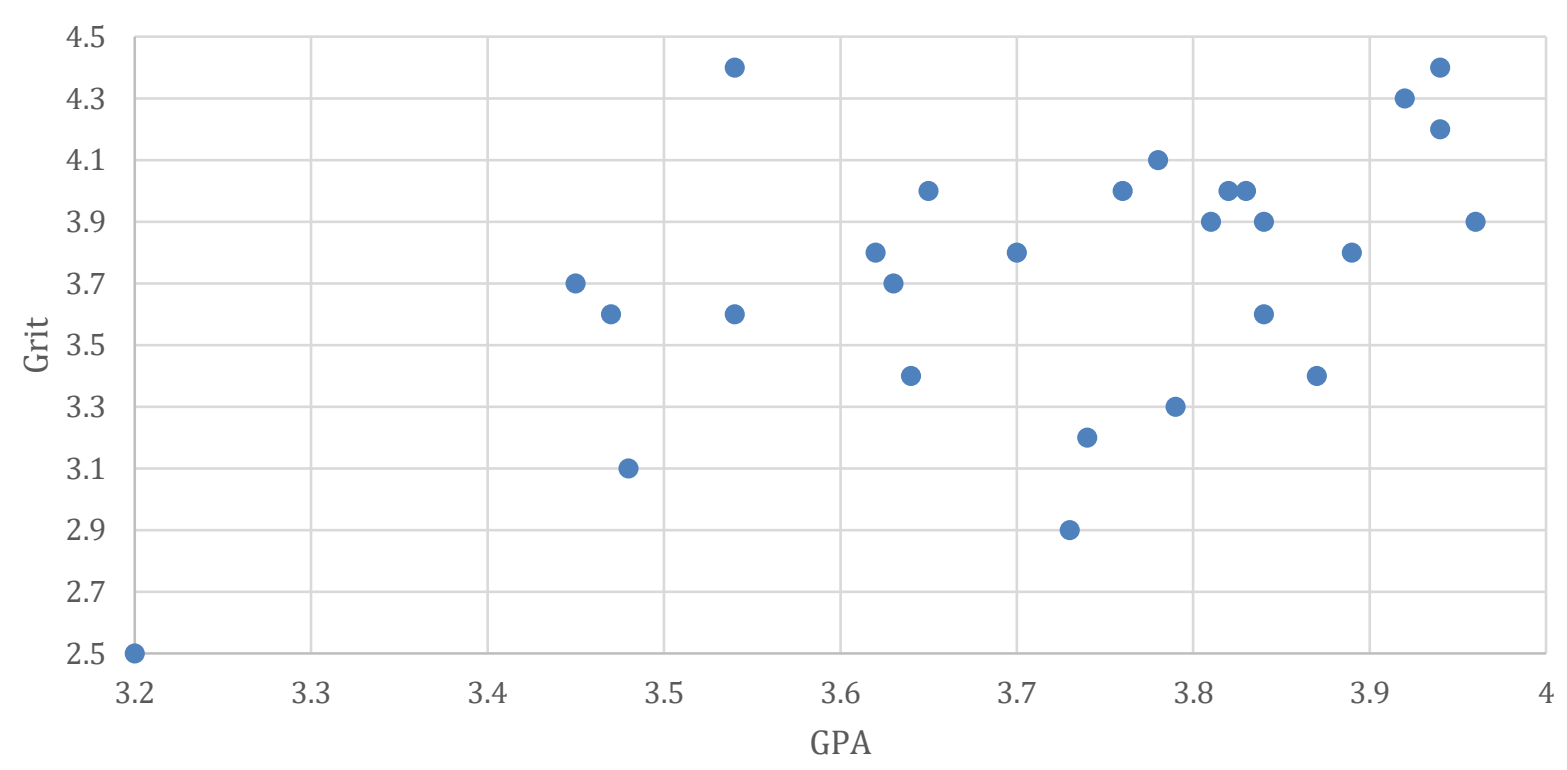

Figure 1. Scatter Plot Graph of Correlation Analysis findings 


\section{DISCUSSION}

The purpose of this study was to examine the correlation between grit and grade point average in Doctor of Physical Therapy students. Grit is paramount in Doctor of Physical Therapy students evidenced by nearly eight years of required post-secondary education, and this conclusion aligns with previous research that expounds the importance of grit in high levels of academic achievement. $3-9$ We found the average grittiness among Franklin Pierce University physical therapy students to be $3.72 \pm 0.45$, slightly higher than previous research from Calo et al who found physical therapy students averaged $3.56 \pm 0.65 .{ }^{9}$ Although this study is the first, to our knowledge, that specifically examined the relationship between grit and grade point average in physical therapy students, other studies have examined the correlation between grit and other scholastic achievement markers in graduate school programs and found similar, positive correlations. $6-8,11$ Understanding the correlation between grit and academic success in physical therapy programs can be applied to self-development coursework after enrollment or used in career guidance in undergraduate programs.

\section{Limitations}

Limitations of this study include the use of narrow convenience sampling and the small number of subjects utilized, reducing the generalizability of our results. In addition, this study was done a one university and may not apply to physical therapy students in other universities. Also, as in any survey research, results may be affected by response bias, acquiescence bias, demand characteristics bias, extreme responding bias, and desirability bias.

\section{Recommendations for Future Research}

Future research is needed to examine how grit scores may be used for admissions considerations. Effects of grit on DPT student clinical performance and graduation rates are interesting topics for future research. In our current progressive age of information, traditional paradigms of candidate selection and training are shifting in the medical field. ${ }^{12} \mathrm{Holistic}$ admissions processes are being considered as a potential method to assess DPT applicants. ${ }^{3-4}$ An understanding of this correlation between grit and academic performance will contribute to these endeavors

\section{Conclusion}

Results of this study demonstrate that grit score and grade point average have a significant positive correlation suggesting that students who are grittier are more likely to experience higher academic achievement. Academic success in didactic work translates to successful student clinical rotations and ultimately graduation. Analysis of non-cognitive personality traits like grit can be used to further the development of competent clinicians. Grit score analysis has the potential to be used for graduate school admissions and as a useful tool for student development.

\section{References}

1. Nuciforo M, Litvinsky, Y, Rheault W. Variables predictive of admission to US physical therapist education programs. J Phys Ther Educ. 2014;28(3);112-119.

2. Duckworth AL, Quirk A, Gallop R, Hoyle, RH, Kelly DR, Matthews MD. Cognitive and noncognitive predictors of success. Proc Natl Acad Sci U S A. 2019;116(47);23499-23504.

3. Roll M, Canham L, Salamh P, Covington K, Simon C, Cook C. A novel tool for evaluating non-cognitive traits of doctor of physical therapy learners in the United States. J Educ Eval Health Prof. 2018;15.

4. Megginson L. Noncognitive constructs in graduate admissions: an integrative review of available instruments. Nurse Educ. 2009;34(6);254-261.

5. Duckworth AL, Quinn PD. Development and validation of the Short Grit Scale (Grit-S). J Pers Assess. 2009; 91(2):166-174. doi:10.1080/00223890802634290.

6. Miller-Matero L, Martinez S, Maclean L, Yaremchuk K, Ko A. Grit: A predictor of medical student performance. Educ Health. 2018;31(2):109. doi:10.4103/efh.efh_152_16.

7. Cross TM. The Gritty: Grit and non-traditional doctoral student success. J Educ Online. 2014;11(3). doi:10.9743/jeo.2014.3.4.

8. Pate AN, Payakachat N, Harrell TK, Pate KA, Caldwell DJ, Franks AM. Measurement of grit and correlation to student pharmacist academic performance. Am J Pharm Educ. 2017;81(6);105. doi:10.5688/ajpe816105.

9. Calo M, Peiris C, Chipchase L, Blackstock F, Judd B. Grit, resilience and mindset in health students. Clin Teach. 2019; 16(4):317-322. doi:10.1111/tct.13056.

10. Stoffel JM, Cain J. Review of grit and resilience literature within health professions education. Am J Pharm Educ. 2018;82(2);6150. doi:10.5688/ajpe6150. 
11. Palisoc AJL, Matsumoto RR, Ho J, Perry PJ, Tang TT, Ip EJ. Relationship between grit with academic performance and attainment of postgraduate training in pharmacy students. Am J Pharm Educ. 2017;81(4);67. doi:10.5688/ajpe81467.

12. Koh GC, Khoo HE, Wong ML, Koh D. The effects of problem-based learning during medical school on physician competency: a systematic review. CMAJ. 2008;178(1);34-41. doi:10.1503/cmaj.070565. 